\title{
Focus Group Discussion (FGD) dengan Interprofessional Education (IPE) sebagai Alternatif Peningkatan Pengetahuan Tenaga Kesehatan tentang Kontrasepsi Oral dan Suntik di Kota Bandung
}

\section{A Focus Group Discussion (FGD) on Interprofessional Education (IPE) as an Alternative to Increase Health Personnel's Knowledge About Oral and Injection Contraceptives in Bandung}

\author{
Ikhwan Yuda Kusuma', Doni Anshar Nuari' ${ }^{2}$, Kusnandar Anggadiredja ${ }^{3}$ \\ ${ }^{1}$ Program Studi Farmasi,Universitas Harapan Bangsa, Jl. Raden Patah No.100, Banyumas, Indonesia \\ ${ }^{2}$ Jurusan Farmasi, Universitas Garut, Jl. Raya Samarang No.52a, Garut, Indonesia \\ ${ }^{3}$ Sekolah Farmasi, Institut Teknologi Bandung, Jl. Ganesha No.10, Lb. Siliwangi, Bandung, Indonesia \\ *E-mail: ikhwanyudakusuma@gmail.com
}

Received: 6 November 2019; Accepted: 26 Desember 2019; Published: 30 Desember 2019

\begin{abstract}
Abstrak
Angka putus pakai kontrasepsi di Indonesia hingga tahun 2016 masih tinggi yaitu mencapai 25,7\% dari target pemerintah sebesar $24 \%$, sehingga optimalisasi kinerja tenaga kesehatan harus ditingkatkan, terutama mengenai pengetahuan tenaga kesehatan tentang penggunaan kontrasepsi oral dan injeksi yang merupakan pengguna kontrasepsi terbesar di kota Bandung. Salah satu upaya untuk meningkatkan kualitas program keluarga berencana, melalui peningkatan kompetensi tenaga kesehatan yang disebut Interprofessional Education (IPE). Tujuan dari penelitian ini adalah untuk mengidentifikasi tingkat pengetahuan tenaga kesehatan di Puskesmas mengenai kontrasepsi oral dan suntikan setelah dilakukan FGD antar profesi dengan IPE di Bandung. Penelitian ini menggunakan metode eksperimen dengan tipe one group pre-posttest design. Data dianalisis menggunakan Wilcoxon rank test dari kuesioner tentang pengetahuan petugas kesehatan tentang kontrasepsi oral dan injeksi pada IPE sebelum dan sesudah Focus Group Discussion (FGD). Hasil penelitian menunjukkan ada peningkatan tingkat pengetahuan pada 152 orang tenaga kesehatan, penurunan tingkat pengetahuan pada 5 orang tenaga kesehatan dan tidak ada perubahan pada empat orang tenaga kesehatan. Focus Group Discussion (FGD) melalui Interprofessional Education (IPE) terbukti secara signifikan meningkatkan pengetahuan tentang kontrasepsi oral dan injeksi pada tenaga kesehatan di Puskesmas.
\end{abstract}

Kata Kunci: Focus Group Discussion, Interprofessional Education, pengetahuan, kontrasepsi

\begin{abstract}
The drop out rate of contraceptive use in Indonesia until 2016 still high at $25.7 \%$ of the government's target of $24 \%$, thus the optimization of the performance of health personnel should be improved, especially regarding health personnel knowledge about the use of oral and contraceptives which is the largest user in the city of Bandung. One of the efforts to improve the quality of family planning programs, through increasing the competence of health workers called Interprofessional Education (IPE). The purpose of this study was to identify the level of knowledge of health personnel at the health center regarding oral and injection contraceptives between professions with IPE in Bandung. This research used an experimental method with the type of group pre-posttest design. Data were analyzed using the Wilcoxon rank test from a questionnaire on health personnel's knowledge about oral and injection contraceptives on IPE before, and after Focus Group Discussion (FGD). The results showed there was an increase in the level of knowledge in 152 health personnel, a decrease in the level of knowledge in 5 health personnel, and no change in the four health personnel. Focus Group Discussion (FGD) through Interprofessional Education (IPE) was proven to significantly increase knowledge about oral contraceptives and injections on health personnel at the Health Center.
\end{abstract}

Keywords: Focus Group Discussion, Interprofessional Education, knowledge, contraceptives 


\section{PENDAHULUAN}

Pembangunan di bidang kesehatan, harus didasarkan pada dinamika kependudukan di mana pertumbuhan penduduk mempengaruhi tingkat kesehatan suatu negara. Badan Pusat Statistik menyatakan terjadi peningkatan jumlah penduduk di Indonesia dengan laju pertumbuhan sebesar $1,19 \%$ pertahun, di mana pada tahun 2015 jumlah penduduk ialah 256.461.700 orang dan diperkirakan naik menjadi 268.074.600 orang pada tahun 2019 . Jumlah wanita usia subur akan meningkat dari tahun 2015 yang diperkirakan sebanyak 68,1 juta menjadi 71,2 juta pada tahun 2019 (Kemenkes, 2015). Berdasarkan jumlah tersebut, diperkirakan ada 5 juta ibu hamil setiap tahun. Angka ini merupakan estimasi jumlah persalinan dan jumlah bayi lahir, yang juga menjadi petunjuk beban pelayanan ANC (Antenatal Care), persalinan, dan neonatus/bayi. Data BPS menunjukkan jumlah penduduk tertinggi terdapat di Provinsi Jawa Barat dengan jumlah penduduk sebesar 46.709.569 jiwa (BPS Indonesia, 2013 dan Kemenkes, 2015).

Upaya pemerintah untuk menekan laju pertumbuhan penduduk ialah melalui program Keluarga Berencana (KB) sebagaimana disampaikan pada Peraturan Pemerintah Republik Indonesia Nomor 87 Tahun 2014 tentang Perkembangan Kependudukan dan Pembangunan Keluarga, Keluarga Berencana, dan Sistem Informasi Keluarga yang menyebutkan bahwa program keluarga berencana (KB) adalah upaya mengatur kelahiran anak, jarak dan usia ideal melahirkan, mengatur kehamilan, melalui promosi, perlindungan, dan bantuan sesuai dengan hak reproduksi untuk mewujudkan keluarga yang berkualitas (Kemenkes, 2014a). Keluarga Berencana (KB) juga dapat mencegah kehamilan berisiko tinggi, yaitu kehamilan dengan kondisi terlalu muda melahirkan (di bawah usia 18 tahun), terlalu sering melahirkan (lebih dari 4 kali), terlalu dekat jarak melahirkan (kurang dari 2 tahun), dan terlalu tua melahirkan (di atas usia 35 tahun) (Senanayake and Potts, 2008).

Data statistik BKKBN hingga Maret 2017 menunjukkan jumlah pengguna KB aktif di Indonesia saat ini ialah sebanyak 23.909.367 akseptor. Berdasarkan data tersebut sebanyak 5.654.907 akseptor berada di Provinsi Jawa Barat dengan 226.337 akseptor KB aktif berasal dari Kota Bandung (BKKBN, 2017). Sebagian besar peserta KB baru maupun KB aktif memilih suntikan dan pil sebagai alat kontrasepsi. Kedua jenis alat kontrasepsi ini dianggap mudah diperoleh dan digunakan oleh pasangan usia subur (Kemenkes, 2014a). Jumlah pengguna KB pil di Kota Bandung sebanyak 34.822 akseptor $(15,39 \%)$, sedangkan pengguna KB suntik sebanyak 98.055 akseptor $(43,32 \%)$ (BKKBN, 2017).

Keluarga Berencana melibatkan 3 dinamika dan elemen interaktif yaitu metode pengaturan di masa subur, pelayanan kesehatan oleh tenaga kesehatan, serta persepsi dan karakteristik akseptor (Senanayake and Potts, 2008). Dalam rangka penguatan dan pencapaian tujuan pelayanan $\mathrm{KB}$ oleh tenaga kesehatan, maka dukungan manajemen pelayanan $\mathrm{KB}$ menjadi sangat penting, mulai dari Perencanaan, Pelaksanaan, serta Pemantauan dan Evaluasi (Kemenkes, 2014b)

Pelayanan KB oleh tenaga kesehatan dalam bentuk sistem informasi dan pendidikan yang komunikatif merupakan faktor yang paling penting dalam optimalisasi kepatuhan akseptor KB serta menjadi pedoman penentuan pilihan kontrasepsi bagi akseptor. Tingkat putus pakai kontrasepsi tahun 2016 mencapai 25,7 \% menjadi sasaran strategis BKKBN 2015-2019 melalui penggunaan MKJP (Model Kontrasepsi Jangka Panjang) untuk mengurangi risiko drop-out dan penggunaan non-MKJP dengan memberikan informasi secara berkesinambungan (BKKBN, 2017). Oleh karena itu, optimalisasi kinerja dan kompetensi petugas pelaksana penyuluhan 
yaitu tenaga kesehatan perlu ditingkatkan sehingga mampu memberikan informasi yang relevan kepada akseptor KB untuk meningkatkan pengetahuan dan kepatuhan akseptor terutama pada penggunaan KB hormonal secara oral dan suntik (Senanayake and Potts, 2008).

Pemberian kontrasepsi oral dan suntik memerlukan tingkat kepatuhan yang tinggi, hal ini dikarenakan tingginya angka kegagalan program KB akibat penurunan efek dan peningkatan potensi efek samping akibat ketidakpatuhan akseptor (Allen dan Cwiak, 2014). IPE merupakan salah satu solusi untuk meningkatkan kompetensi tenaga kesehatan. Kolaborasi dua atau lebih profesi bertujuan untuk membina interaksi interprofessional yang meningkatkan praktek disiplin masingmasing profesi (Barr dan Low, 2013). Levi,dkk. (2013) dan Cappiello, dkk. (2016) menjelaskan kolaborasi antarprofesi kesehatan dalam bentuk Interprofessional Education mampu meningkatkan kualitas pelayanan kesehatan melalui peningkatan kompetensi di seluruh disiplin ilmu dan profesi dalam perawatan kesehatan seksual dan reproduksi.

IPE merupakan satu upaya mewujudkan program pelayanan KB yang berkualitas. IPE mampu mengidentifikasi tingkat pengetahuan tenaga kesehatan terkait obat kontrasepsi, menganalisis faktor-faktor yang berhubungan dengan kompetensi tenaga kesehatan dalam kegiatan penyuluhan $\mathrm{KB}$, dan mampu menentukan informasi penting yang harus akseptor ketahui terkait penggunaan $\mathrm{KB}$ oral dan suntik. Oleh karena itu perlu dilakukan penelitian untuk mengevaluasi tingkat pengetahuan tenaga kesehatan terkait $\mathrm{KB}$ oral dan suntik melalui FGD Interprofessional Education di beberapa Puskesmas di kota Bandung.

\section{METODE PENELITIAN}

Penelitian ini menggunakan metode eksperimental dengan rancangan penelitian one group pre-posttest design. Penelitian ini dimulai dengan melakukan uji validitas dan reliabilitas kuesioner kepada tenaga kesehatan yang di adaptasi dari RIPLS (Readiness for Inter-professional Learning Scale Questionnaire) (Parsell dan Bligh, 1999). Responden diberikan kuesioner Pre-Test untuk mengetahui tingkat pengetahuan tenaga kesehatan tentang KB oral dan suntik selama kurang lebih 20 menit. Penelitian dilanjutkan dengan pemberian penjelasan oleh peneliti kepada tenaga kesehatan di Puskesmas terkait konsep IPE dan dilakukan Focus Group Discussion dengan peserta tenaga kesehatan di Puskesmas yang terdiri dari minimal 2 profesi berbeda. Responden diberikan kuesioner Post -Test untuk mengetahui pengetahuan tenaga kesehatan tentang KB oral dan suntik setelah FGD. Pengumpulan informasi dilakukan menggunakan kuesioner (terlampir) dan peneliti menyeleksi kembali kuesioner yang tidak terisi dengan lengkap, dan hanya mengambil kuesioner yang diisi dengan lengkap. Kuesioner yang telah diisi selanjutnya diolah dan dianalisa oleh peneliti.

\section{Subjek Penelitian}

Penelitian ini menggunakan teknik sampling area (cluster). Subyek penelitian ditetapkan oleh Badan Pemberdayaan Perempuan dan Keluarga Berencana (BPPKB) Kota Bandung dan Dinas Kesehatan Kota Bandung, yaitu tenaga kesehatan yang bertanggung jwawab di UPT Puskesmas Caringin, UPT Puskesmas Talaga Bodas, UPT Puskesmas Padasuka, UPT Puskesmas Margahayu Raya, UPT Puskesmas Ujung Berung, dan UPT Puskesmas Garuda. Subjek dalam penelitian ini ditentukan melalui kriteria inklusi dan kriteria eksklusi. Kriteria inklusi dalam penelitian ini adalah tenaga kesehatan (apoteker, asisten apoteker, dokter, perawat, bidan, dan Sarjana Kesehatan Masyarakat) di Puskesmas yang bertanggungjawab dan berkaitan langsung dalam pelayanan KB dan Petugas Lapangan KB (PLKB) penanggungjawab di tingkat kecamatan. Subjek yang memenuhi kriteria inklusi akan ditanyakan kesediaan untuk ikut serta dalam penelitian ini melalui Informed Consent yang 
terlampir pada lampiran. Kriteria eksklusi dalam penelitian ini adalah tenaga kesehatan yang tidak terkait langsung dengan pelayanan KB dan PLKB yang belum pernah mengikuti pelatihan terkait pelayanan KB.

\section{Data dan Sumber Data}

Data dalam penelitian ini menggunakan data primer yang diperoleh dari responden dengan daftar pertanyaan yang terdapat pada kuesioner mengenai pengetahuan tenaga kesehatan tentang $\mathrm{KB}$ oral dan suntik terhadap IPE sebelum dan setelah dilakukan FGD (Focus Group Discussion) antar profesi tenaga kesehatan.

\section{Tempat dan Waktu Penelitian}

Penelitian dilaksanakan di UPT Puskesmas Caringin, UPT Puskesmas Talaga Bodas, UPT Puskesmas Padasuka, UPT Puskesmas Margahayu Raya, UPT Puskesmas Ujung Berung, dan UPT Puskesmas Garuda. Validasi kuesioner dilakukan pada bulan Desember hingga Januari 2017, kemudian dilakukan penelitian dengan kuesioner pada bulan Januari hingga Febuari 2018.

\section{Analisis Data}

Kuesioner mengenai pengetahuan tentang KB oral dan suntik diujicobakan dahulu untuk dinilai validitas dan reliabilitasnya. Validitas kuesioner diuji dengan teknik korelasi Pearson Product Moment untuk melihat nilai korelasi antara skor masing-masing variabel dengan skor totalnya, sedangkan reliabilitas kuesioner diuji dengan menggunakan Croncbach Alpha. Cronbach's alpha secara simultan akan membandingkan skala setiap item yang satu dengan yang lainnya. (Jones, 2010 dan Swarjana, 2016).

Pengolahan data pada penelitian ini dilakukan menggunakan program SPSS (Statistical Product and Service Solution) Statistik 24. Cara analisis data sebagai berikut dimulai dengan menentukan hipotesis :

a Ha: ada perbedaan yang signifikan terkait pengetahuan $\mathrm{KB}$ oral dan suntik tenaga kesehatan sebelum dan setelah IPE Focus Group Discussion b. Ho: tidak ada perbedaan yang signifikan terkait pengetahuan $\mathrm{KB}$ oral dan suntik tenaga kesehatan sebelum dan setelah IPE Focus Group Discussion.

$\mathrm{H}_{0}$ Diterima $=$ Signifikansi $>0,05=$ tidak ada perbedaan yang signifikan terkait pengetahuan $\mathrm{KB}$ oral dan suntik tenaga kesehatan sebelum dan setelah IPE Focus Group Discussion, sedangkan $\mathrm{H}_{0}$ Ditolak = Signifikansi $\leq 0,05=$ ada perbedaan yang signifikan terkait pengetahuan KB oral dan suntik tenaga kesehatan sebelum dan setelah IPE Focus Group Discussion.

Cara mengukur penilaian pengaruh pemberian IPE dalam Focus Group Discussion terhadap pengetahuan tentang KB oral dan suntik pada tenaga kesehatan dilakukan melalui pendekatan kuantitatif melalui kuesioner dengan skala Guttman. Skala Guttman adalah skala pengukuran untuk mendapatkan jawaban yang tegas terhadap suatu permasalahan yang ditanyakan (Sugiyono, 2016). Kuesioner dibuat dengan pertanyaan benar-salah, jika jawaban tepat diberi skor 1 dan jika tidak tepat diberi skor 0 .

Cara mengukur penilaian pengetahuan tenaga kesehatan terhadap IPE dalam Focus Group Discussion dilakukan melalui pendekatan kuantitatif melaui kuesioner dengan skala Likert dimana variabel yang akan diukur dijabarkan menjadi indikator variabel (Sugiyono, 2016). Kuesioner tingkat pengetahuan terdiri dari 25 pertanyaan, jika jawabannya SS (Sangat Setuju) diberi skor 6, S (Setuju) diberi skor 5, AS (Agak Setuju) diberi skor 4, ATS (Agak Tidak Setuju) diberi skor 3, TS (Tidak Setuju) diberi skor 2, STS (Sangat Tidak Setuju) diberi skor 1.

Penilaian pengaruh pemberian IPE dalam

Focus Group Discussion terhadap pengetahuan tentang $\mathrm{KB}$ oral dan suntik pada tenaga kesehatan dilakukan dengan menggunakan Willcoxon rank test. Willcoxon rank test merupakan uji nonparametrik yang digunakan untuk uji beda pada 2 kelompok sampel yang berpasangan, dengan skala 
ordinal. Uji Willcoxon rank test digunakan sebagai uji alternatif dari uji $\mathrm{T}$ berpasangan (Paired t-test) yang tidak memenuhi syarat selisih data berpasangan harus berdistribusi normal (Jones, 2010, Swarjana, 2016, dan Sugiyono, 2016). Group yang dilihat adalah tenaga kesehatan aktif dan yang diukur adalah pengaruh pemberian IPE dalam Focus Group Discussion terhadap pengetahuan tentang KB oral dan suntik. Pada analisis ini peneliti hanya akan melihat mean antar kelompok dan signifikansi antar komponen.

\section{HASIL DAN PEMBAHASAN}

Sebelum digunakan untuk pengambilan data, kuesioner mengenai pengetahuan $\mathrm{KB}$ oral dan suntik dan kuesioner terkait pengaruh pemberian IPE dalam FGD diujicobakan terlebih dahulu pada 51 orang responden dengan kriteria inklusi yang sama dengan responden yang akan diteliti. Validitas kuesioner diuji dengan teknik korelasi Pearson Product Moment. Output korelasi Pearson Product Moment tentang kuesioner tingkat pengetahuan, nilai output tersebut kemudian dibandingkan dengan nilai $\mathrm{r}$ tabel $(\mathrm{n}=51)$ pada signifikansi 0,05 yaitu 0,2706. Berdasarkan hasil output korelasi Pearson Product Moment dengan menggunakan SPSS 24 diketahui bahwa semua nilai $r$ hitung $>r$ tabel artinya 25 pertanyaan yang diuji dinyatakan valid, dan layak untuk dijadikan pertanyaan pada kuesioner tentang pengetahuan tenaga kesehatan tentang $\mathrm{KB}$ oral dan suntik

Kuesioner selanjutnya diuji kembali dengan uji reliabilitas. Reliabilitas kuesioner diuji dengan menggunakan metode Croncbach Alpha. Hasil uji reliabilitas dengan nilai Croncbach Alpha adalah 0,894, nilai ini kemudian dibandingkan dengan nilai $\mathrm{r}$ tabel $(\mathrm{n}=51)$ pada signifikansi 0,05 yaitu 0,2706 . Berdasarkan hasil output diketahui bahwa nilai $\mathrm{r}$ hitung $>\mathrm{r}$ tabel artinya kuesioner tersebut reliable dengan reliabilitas sangat tinggi.

\section{Hasil Uji Normalitas Data Kuesioner}

Pengaruh pemberian IPE dalam Focus Group Discussion terhadap pengetahuan tentang KB pada tenaga kesehatan dilakukan dengan menggunakan Willcoxon rank test. Data hasil uji normalitas kuesioner pengetahuan pada 6 puskesmas di Kota Bandung dengan metode KolmogorovSmirnov dan Shapiro-Wilk disajikan pada Tabel 1.

Tabel 1. Uji Normalitas Data Tingkat Pengetahuan Tenaga kesehatan tentang KB oral dan suntik

\begin{tabular}{ccccccc}
\hline & \multicolumn{3}{c}{$\begin{array}{c}\text { Kolmogorov- } \\
\text { Smirnov }^{a}\end{array}$} & \multicolumn{3}{c}{ Shapiro-Wilk } \\
\cline { 2 - 7 } & $\begin{array}{c}\text { Stati } \\
\text { stic }\end{array}$ & $d f$ & Sig. & $\begin{array}{c}\text { Stati } \\
\text { stic }\end{array}$ & $d f$ & Sig. \\
\hline $\begin{array}{c}\text { Selisih } \\
\text { Pre- } \\
\text { Post }\end{array}$ & .109 & 161 & .000 & .978 & 161 & .011 \\
Test & & & & & & \\
\hline \multicolumn{3}{c}{ a. Lilliefors Significance Correction }
\end{tabular}

Data pada tabel 1, hasil uji normalitas dengan metode Kolmogorov-Smirnov dan Shapiro-Wilk pada data tingkat pengetahuan tenaga kesehatan di Kota Bandung menunjukkan $p$-value pada KolmogorovSmirnov adalah $0,000<\alpha 0,05$, sementara nilai $p$-value pada Shapiro-Wilk adalah 0,011 $<\alpha 0,05$, artinya nilai $\mathrm{p}<0,05$ sehingga selisih nilai berpasangan tersebut berbeda signifikan dengan sebaran data normal artinya sebaran data selisih nilai berpasangan tidak berdistribusi normal, tidak dapat dilakukan uji secara parametrik namun dapat menggunakan uji non parametrik dengan metode Willcoxon rank test sebagai alternatif.

\section{Pengaruh FGD IPE terhadap Tingkat Pengetahuan Tenaga Kesehatan}

Data demografi responden dapat dilihat pada Tabel 2, yang meliputi jumlah tenaga kesehatan pada masing-masing puskesmas, jenis kelamin, umur, profesi, tingkat pendidikan, dan masa kerja. 
Tabel 2. Data Demografi Responden

\begin{tabular}{lcc}
\hline \multicolumn{1}{c}{ Variabel } & $\begin{array}{c}\text { Jumlah } \\
\text { Tenaga } \\
\text { kesehatan }\end{array}$ & \\
\hline Puskesmas & & \\
UPT Caringin & 30 & $18,63 \%$ \\
UPT Garuda & 32 & $19,88 \%$ \\
UPT Margahayu & 23 & $14,29 \%$ \\
Raya & & \\
UPT Padasuka & 34 & $21,12 \%$ \\
UPT Talaga Bodas & 21 & $13,04 \%$ \\
UPT Ujung Berung & 21 & $13,04 \%$ \\
Jenis Kelamin & & \\
Laki-laki & 18 & $11,18 \%$ \\
Perempuan & 143 & $88,82 \%$ \\
Usia & & \\
21 - 25 tahun & 19 & $11,80 \%$ \\
26-30 tahun & 68 & $42,24 \%$ \\
31 - 35 tahun & 53 & $32,92 \%$ \\
36-40 tahun & 16 & $9,94 \%$ \\
Di atas 40 tahun & 5 & $3,11 \%$ \\
Profesi & & \\
Apoteker & 6 & $3,73 \%$ \\
Dokter & 27 & $16,77 \%$ \\
Perawat & 42 & $26,09 \%$ \\
Bidan & 48 & $29,81 \%$ \\
SKM & 22 & $13,66 \%$ \\
Asisten Apoteker & 9 & $5,59 \%$ \\
PLKB & 7 & $4,35 \%$ \\
Tingkat Pendidikan & & \\
SMK & 4 & $2,48 \%$ \\
D3 & 72 & $44,72 \%$ \\
S1 & 44 & $27,33 \%$ \\
Profesi & 40 & $24,84 \%$ \\
S2/Spesialis & 1 & $0,62 \%$ \\
Masa Kerja & & \\
< 10 tahun & 107 & $66,46 \%$ \\
$>10$ tahun & 54 & $33,54 \%$ \\
\hline & & \\
\hline
\end{tabular}

Hipotesis penelitian ini adalah adanya perbedaan yang signifikan terkait pengetahuan tentang kontrasepsi oral dan suntik terhadap IPE oleh tenaga kesehatan sebelum dan setelah IPE Focus Group Discussion. Pembuktian hipotesis dilakukan dengan menggunakan statistik non parametrik yaitu uji Wilcoxon sign rank test.

Hasil pengujian hipotesis statistik penelitian dengan menggunakan analisis program SPSS Uji Wilcoxon Signed Rank Test menunjukkan hasil seperti pada Tabel 3.
Tabel 3. Hasil analisis deskriptif tingkat pengetahuan tenaga kesehatan tentang KB oral dan suntik pada saat Pretest - Postest Descriptive Statistics

\begin{tabular}{|c|c|c|c|c|c|}
\hline & \multicolumn{5}{|c|}{ 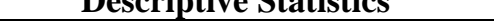 } \\
\hline & $\mathrm{N}$ & Mean & $\begin{array}{l}\text { Std. } \\
\text { Dev. }\end{array}$ & Min. & Max \\
\hline $\begin{array}{l}\text { Pre Test } \\
\text { Pengetahuan }\end{array}$ & 161 & 15.50 & 2.530 & 9 & 23 \\
\hline $\begin{array}{l}\text { Post Test } \\
\text { Pengetahuan }\end{array}$ & 161 & 19.32 & 2.024 & 14 & 23 \\
\hline
\end{tabular}

Hasil analisis deskriptif pada tabel 3 dapat dilihat bahwa terdapat perbedaan tentang tingkat pengetahuan tenaga kesehatan antara data pretest dan posttest tentang $\mathrm{KB}$ oral dan suntik. Hasil analisis data pengukuran tingkat pengetahuan tenaga kesehatan tentang $\mathrm{KB}$ oral dan suntik pada pretest diperoleh mean $(\mathrm{M})=15,50 \pm 2,530$. Setelah IPE Focus Group Discussion dilakukan, pengujian kembali (post test) dilakukan dan diperoleh mean $(\mathrm{M})=19,32 \pm 2,024$. Hasil ini menunjukkan bahwa IPE Focus Group Discussion mampu meningkatkan pengetahuan tenaga kesehatan tentang $\mathrm{KB}$ oral dan suntik dengan variabilitas (presisi) data dalam kelompok puskesmas tersebut yang semakin menyempit artinya penyimpangan tidak terlalu mencolok (Jones, 2010). Nilai minimum terendah pada saat pre test adalah 9 meningkat pada saat posttest hingga mencapai 14, meskipun nilai maksimum dari semua responden dari semua puskesmas tetap yaitu 23 .

Berdasarkan hasil analisis Wilcoxon Signed Rank Test pada tabel 4 tentang tingkat pengetahuan tenaga kesehatan pada saat Pretest dan Postest digambarkan dalam bentuk rank (peringkat). Negative ranks atau selisih negatif artinya sampel dengan nilai kelompok kedua (posttest) lebih rendah dari nilai kelompok pertama (pretest), dalam penelitian ini diperoleh 5 data negatif $(\mathrm{N})$ artinya 5 orang tenaga kesehatan mengalami penurunan tingkat pengetahuan, rata-rata penurunan (mean rank) tersebut adalah sebesar 25,40, sedangkan jumlah rangking negatif (sum of rank) adalah 127,00. 
Tabel 4. Hasil analisis Wilcoxon Signed Rank Test tingkat pengetahuan tenaga kesehatan tentang KB oral dan suntik pada saat Pretest - Postest

\begin{tabular}{|c|c|c|c|c|}
\hline & & & Ranks & \\
\hline & & & Mean & Sum of \\
\hline & & $N$ & Rank & Ranks \\
\hline Post Test & Negative & $5^{a}$ & 25.40 & 127.00 \\
\hline $\begin{array}{c}\text { Pengetahuan } \\
\text { - Pre Test }\end{array}$ & Ranks & & & \\
\hline Pengetahuan & $\begin{array}{l}\text { Positive } \\
\text { Ranks }\end{array}$ & $152^{b}$ & 80.76 & 12276.00 \\
\hline
\end{tabular}

\begin{tabular}{cc} 
Ties & $4^{c}$ \\
Total & 161 \\
\hline a. Post Test Pengetahuan $<$ Pre Test Pengetahuan \\
b. Post Test Pengetahuan $>$ Pre Test Pengetahuan \\
c. Post Test Pengetahuan $=$ Pre Test Pengetahuan
\end{tabular}

Positive ranks atau selisih positif artinya sampel dengan nilai kelompok kedua (posttest) lebih tinggi dari nilai kelompok pertama (pretest), dalam penelitian ini diperoleh 152 data positif artinya 152 orang tenaga kesehatan mengalami peningkatan tingkat pengetahuan, rata-rata peningkatan (mean rank) tersebut adalah sebesar 80,76, sedangkan jumlah rangking positif (sum of rank) adalah 12276.00. Sedangkan ties adalah nilai kelompok kedua (posttest) sama besarnya dengan nilai kelompok pertama (pretest), dalam penelitian ini diperoleh 4 data $(\mathrm{N})$ artinya 4 orang tenaga kesehatan tidak mengalami peningkatan maupun penurunan tingkat pengetahuan.

Data pada Tabel 5 menunjukkan hasil uji hipotesis dengan menggunakan output SPSS 24 yaitu data Test Statistics. Dasar pengambilan keputusan dalam uji Wilcoxon Signed Rank Test adalah jika nilai Asymp. Sig. (2-tailed) lebih kecil dari 0,05 $(<\alpha 0,05)$ maka Ha diterima, begitupula sebaliknya (Jones, 2010).

Berdasarkan data Test Statistics diketahui nilai Asymp. Sig. (2-tailed) adalah 0,000, karena nilai $0,000<0,05$ maka dapat disimpulkan bahwa Ha diterima, artinya ada perbedaan yang signifikan terkait pengetahuan $\mathrm{KB}$ oral dan suntik tenaga kesehatan sebelum dan setelah IPE Focus Group Discussion, sehingga dapat disimpulkan bahwa ada pengaruh IPE Focus Group Discussion terhadap tingkat pengetahuan tenaga kesehatan di Kota Bandung.

Tabel 5. Hasil Uji Hipotesis dengan Wilcoxon Signed Rank Test tentang tingkat pengetahuan tenaga kesehatan tentang KB oral dan suntik

\begin{tabular}{|c|c|}
\hline \multicolumn{2}{|c|}{$\begin{array}{l}\text { Test Statistics }{ }^{a} \\
\text { 'st Test - Pre Test Pengetahuan }\end{array}$} \\
\hline$Z$ & $-10.676^{b}$ \\
\hline $\begin{array}{c}\text { Asymp. Sig. } \\
\text { (2-tailed) }\end{array}$ & .000 \\
\hline
\end{tabular}

Penelitian ini sejalan dengan penelitian yang dilakukan oleh (Evans, dkk, 2017) yang menyatakan bahwa proyek IPE mampu meningkatkan pengetahuan secara signifikan, dan menunjukkan sikap terhadap kolaborasi positif secara keseluruhan. Kim (2010) juga menyatakan bahwa kolaborasi IPE tidak hanya membantu dalam meningkatkan kemampuan dan pengetahuan terkait topik tertentu, tetapi juga membantu mengenali dan menghargai proses kerja di dalam sebuah tim.

Penelitian ini sejalan dengan penelitian Maeno dkk. (2013) yang menyatakan bahwa IPE membantu siswa dalam meningkatkan pemahaman mereka tentang pekerjaan interprofesional, meskipun sistem perawatan kesehatan dan sistem pendidikan berbeda dengan negara barat, namun pendidikan interpersonal di jepang dan negara lain akan serupa dengan yang terjadi di negara barat. Penelitian Fallatah, dkk (2015) juga menyatakan bahwa penerapan IPE dalam pendidikan mereka akan memperbaiki kepuasan pasien dan perawatan terhadap pasien serta peningkatan persepsi siswa terhadap efektivitas IPE yang berefek pada peningkatkan kemampuan kerja sama tim dan keterampilan komunikasi.

\section{KESIMPULAN}

Focus Group Discussion melalui IPE mampu meningkatkan pengetahuan tenaga kesehatan tentang kontrasepsi KB oral dan suntik di kota Bandung. 


\section{Daftar Pustaka}

Allen, R. H. and Cwiak, C. A., 2014. Contraception for the Medically Challenging Patient. Edited by R. H. Allen and C. A. Cwiak. New York, NY: Springer New York.

Badan Pusat Statistik Indonesia. 2013. Proyeksi Penduduk Indonesia Indonesia Population Projection 2010-2035. Jakarta: Badan Pusat Statistik Indonesia.

Barr, H. and Low, H., 2013. CAIPE: Introducing Interprofessional Education. Fareham: CAIPE.

BKKBN. 2017. Sinergi Dukungan Kegiatan dan Anggaran BKKBN dalam Peningkatan Pelayanan KB di Fasilitas Kesehatan. Jakarta: Badan Kependudukan dan Keluarga Berencana Nasional.

Cappiello, J., Levi, A. and Nothnagle, M., 2016. Core competencies in sexual and reproductive health for the interprofessional primary care team. Elsevier. Elsevier Inc, 93, pp. 438445.

Evans, E. W., Bigler, T., Murray, L., and Wright, C., 2017. Improving knowledge and attitudes of physician assistant and occupational therapy students using interprofessional case studies: Lessons learned, Journal of Interprofessional Education \& Practice. Elsevier Inc, 6, pp. 45-48.

Fallatah, H. I., Jabbad, R. and Fallatah, H. K., 2015. Interprofessional Education as a Need: The Perception of Medical, Nursing Students and Graduates of Medical College at King Abdulaziz University', Scientific Research Publishing. Jeddah, 6, pp. 248-254.

Jones, D. S. 2010. Statistik Farmasi. Jakarta: Penerbit Buku Kedokteran EGC.

Kemenkes. 2014a. Pedoman Manajemen: Pelayanan Keluarga Berencana. Jakarta: Direktorat Jenderal Bina Kesehatan Ibu Kemenkes.

Kemenkes. 2014b. Peraturan Menteri Kesehatan Republik Indonesia Nomor 75 Tahun 2014 tentang Pusat Kesehatan Masyarakat. Jakarta: Kementerian Kesehatan Republik Indonesia.

Kemenkes. 2015. Rencana Strategis Kementerian Kesehatan 2015 - 2019. Indonesia: Kementerian Kesehatan Republik Indonesia.

Kim, J., Sinclair, L., Lowe, M., Srinivasan, V., Gairy, P., 2010. Enhancing capacity for interprofessional collaboration: A resource to support program planning. Toronto: Toronto Rehabilitation Institute.

Levi, A., Burdette, L., Hill-Besinque, K., and Murphy, P. A., 2013. The interprofessional sexual and reproductive health care team. Elsevier. Elsevier Inc., 88, pp. 213-214. 
Maeno, T., Takayashiki, A., Anme, T., Tohno, E., Maeno, T., and Hara, A., 2013. Japanese students' perception of their learning from an interprofessional education program: a qualitative study. International Journal of Medical Education, 4, pp. 9-17.

Parsell, G. and Bligh, J., 1999. The development of a questionnaire to assess the readiness of health care students for interprofessional learning (RIPLS). Medical Education, 33, pp. 95-100.

Senanayake, P. and Potts, M., 2008. Atlas of Contraception 2nd edition. Journal of Obstetrics and Gynaecology, Chennai: Replika Press Pvt Ltd, 28(6), pp. 665-665.

Sugiyono. 2016. Metode Penelitian Kuantitatif, kualitatif dan R \& D. Bandung: Alfa Beta.

Swarjana, I. K. 2016. Statistik Kesehatan. Yogyakarta: CV Andi Offset. 